\title{
THE WORK OF EMPOASCA MALI ON POTATO FOLIAGE
}

By P. J. Parrott and R. D. Olmstead

\section{SUmmary}

This paper presented details of nine cage experiments and one field experiment to determine the effects of attacks of Empoasca mali LeBaron on potato foliage.

In all the experiments, feeding by the insects produced at first small brownish areas of one quarter of an inch or more in width at the tips and occasionally on the margins of the leaflets. The injury became more conspicuous as the season advanced, the brownish or burned areas increasing both in extent and numbers. The discoloration progressed from the tip towards the base of the leaf, and from the margins towards the midrib. As the tissues became desiccated the margins rolled up over the upper surface, leaving a small narrow strip of green tissue in the central area of the leaflet. In instances where such injurics were severe, all the leaflets curled and completely dried up, while the petioles often withered and dried so that any slight disturbance produced defoliation.

In the field test the planting comprised forty-two rows that were one hundred and eighty feet in length. The variety of potato grown was Enormous No. 9. The purpose of this experiment was to determine the repellent effects of the usual spraying mixtures upon leafhoppers as compared with mixtures of heavier consistency. Applications were made of the following preparations: (1), bordeaux mixture (10-10$100)$; (2), bordeaux mixture (10-10-100) with 6 pounds of paste lead arsenate; (3), china clay, 60 pounds to 100 gallons of water to which were added 10 pounds of soap; and (4), bordeaux mixture (8-8-100) with 60 pounds of lump lime. Four rows or more were sprayed with each mixture and two rows were reserved as checks. The applications were made with a power sprayer at a pressure of 100 to 150 pounds, and great care was exercised to cover thoroughly each plant, especially the under sides of the leaves. The first treatment was made on July 8. As rains had washed to a considerable extent the spraying materials from the foliage and the leafhoppers were invading the treated plats, a second application was made on July 16 . Heavy rains occurred again within the next ten days, which necessitated a third treatment on July 28. The last application was made on August 25, which later developments indicated should have been made earlier and followed with another treatment two weeks later. Counts were made of adult leafhoppers at more or less regular intervals, which showed plainly that all the spraying mixtures had exerted considerable influence as repellents. Moreover, at no time during the season were the nymphs 
abundant on the sprayed rows. Nevertheless, nymphs were observed on the vines, and during the latter part of August occasional burned tips were found on the sprayed plants, which was attributed to the unavoidable postponement of the fourth spraying. The marked feature of the test was that the check plants showed during August burned tips and margins of the leaflets, while in early September they rapidly declined. At this time the sprayed vines presented in the main luxuriant foliage with only slight traces of injury; while the checks, in striking contrast to them, were inferior in size and had scanty foliage, which was to a large extent badly shriveled and brownish in appearance. It should also be noted that several experts in plant diseases, who had followed with interest the various developments in this experiment, pronounced the injury to the checks as undistinguishable from the disease known as tip-burn.

The heavy washes, composed of china clay or lime, were a little more effective in repelling the insects than the other spraying mixtures. These sprays, in spite of their heavy consistency, caused very little trouble in clogging the nozzles, and produced a thick coating of the foliage. However, some objectionable features developed which should be noted. The china clay was more easily removed from the foliage by rains than any of the other mixtures, in spite of the fact that it was combined with soap, while lime caused injuries to the foliage. The damage was first noted on July 29 when the third application was made, and after this date the injury considerably increased. Because of the serious damage, the heavy limewash was the least satisfactory of the various mixtures that were tested. Although the bordeaux mixture alone or in combination with lead did not prove as effective a repellent as the sprays of heavier consistency, it should be emphasized that thorough spraying of all surfaces of the leaves of potato plants prevented serious damage by leafhoppers. Furthermore, this spray withstood the washing effects of the rains much better than china clay or lime, the combination with lead proving somewhat superior to bordeaux mixture alone.

Mr. E. G. KeLly: In regard to Bordeaux-lime, do you make your Bordcaux and then add an excess of lime to it?

Mr. P. J. Parrott: Yes.

Mr. E. G. Kelly: What is the effect on the Bordeaux?

Mr. P. J. ParrotT: I am not able to answer your question, as we have not submitted samples of this combination to our chemists for analysis. In this particular planting we did not suffer from late blight, but I do not recommend the addition of large amounts of lime 
for the spraying of potatoes, because of the danger of injury to the plants. However, with both apples and pears large amounts of lime may be applied with little fear of injury.

Mr. LeRoY ChILdS: In my experimental work I found sulphur dust could be used for control. I am wondering if any work with dust has been carried on.

Mr. P. J. Parrott: No.

Mr. Leonard Haseman: This work on potato leafhopper bears directly on one of our projects. I would like to ask Mr. Parrott whether in his opinion the burning is due to the sucking of sap or to the possible introduction of poison?

Mr. P. J. Parrott: My opinion is that with plant lice and insects of that character there is not only injury as a result of the extraction of the juices of the plant, but $I$ think there is something in the salivary secretions of the insects which is toxic to plant tissues and thus accentuates the injury.

Mr. E. D. BALL: I would like to raise one further question. We have a large number of sucking insects occurring on a large number of plants. It does not seem to make any difference what plant the potato leafhopper feeds on, whether a potato plant, a Dahlia, a boxelder, an apple tree or a raspberry bush, it always causes this burning. We have leafhoppers on practically every one of those plants, and none of them produce anything of the kind. The burning is limited to a specific insect. Further than that, the explanation is very largely yet to come.

Vice-President A. G. Ruggles: The next paper is "The Strawberry Root Worm Injuring Roses in Greenhouses," by C. A. Weigel and E. L. Chambers.

\section{THE STRAWBERRY ROOT-WORM INJURING ROSES IN GREENHOUSES}

By C. A. Weiger and E. L. Chambers

The immediate circumstances leading up to this investigation were the simultaneous reports received by the Bureau of Entomology concerning two widely separated infestations of an insect injuring roses in greenhouses at Alexandria, Virginia, and Richmond, Indiana. The specimens which accompanied these reports upon examination were found to be a chrysomelid beetle, the strawberry root-worm, Paria canellus Fab. ${ }^{1}$ This pest though frequently reported as a serious enemy of strawberries, has hitherto not been reported as injurious to

${ }^{1}$ Fabricius, J. E., 1801, Syst. Eleut., p. 52, Vol. 2. 